\title{
Safety of gadobutrol in over 23,000 patients: the GARDIAN study, a global multicentre, prospective, non-interventional study
}

\author{
Martin R. Prince ${ }^{1,14} \cdot$ Hae Giu Lee ${ }^{2}$ Chang-Hee Lee ${ }^{3} \cdot$ Sung Won Youn ${ }^{4}$ In Ho Lee ${ }^{5}$. \\ Woong Yoon $^{6}$ • Benqiang Yang ${ }^{7}$ - Haiping Wang ${ }^{8}$ • Jin Wang ${ }^{9}$ • \\ Tiffany Ting-fang Shih ${ }^{10}$ • Guo-Shu Huang ${ }^{11}$ • Jiing-Feng Lirng ${ }^{12}$ • Petra Palkowitsch ${ }^{13}$. \\ on behalf of the GARDIAN study group
}

Received: 3 September 2015 / Revised: 19 January 2016 / Accepted: 2 February 2016 / Published online: 9 March 2016

(C) The Author(s) 2016. This article is published with open access at Springerlink.com

\begin{abstract}
Objectives To investigate the safety and tolerability of gadobutrol at the recommended dose in patients requiring contrastenhanced magnetic resonance imaging/angiography (MRI/ MRA) in the routine setting.

Methods GARDIAN prospectively enrolled 23,708 patients undergoing routine gadobutrol-enhanced MRI/MRA for approved indications at 272 study centres in Europe, Asia, North America, and Africa and monitored for adverse events.

Results Median gadobutrol dose was $0.11 \mathrm{mmol} / \mathrm{kg}$ body weight. The overall incidence of adverse drug reactions (ADRs) was $0.7 \%$ ( $n=170$ patients), with similar incidences in patients with renal impairment or cardiac disease, from different geographic regions and in different gadobutrol dose groups. Patients at risk for contrast media reaction had an ADR incidence of $2.5 \%$. Five patients $(0.02 \%)$ experienced
\end{abstract}

Martin R. Prince

map2008@med.cornell.edu

on behalf of the GARDIAN study group

1 Department of Radiology, Weill Cornell Medical College, 416 east 55th Street, New York, NY 10022, USA

2 Department of Radiology, Seoul St. Mary's Hospital, The Catholic University of Korea, College of Medicine, Seoul, South Korea

3 Department of Radiology, Korea University Guro Hospital, Seoul, South Korea

4 Department of Radiology, Catholic University of Daegu Medical Center, Daegu, South Korea

5 Department of Radiology, Chungnam National University Hospital, Chungnam National University School of Medicine, Daejeon, South Korea

6 Department of Radiology, Chonnam National University Hospital, Gwangju, South Korea serious adverse events, four were drug-related. One patient experienced a fatal anaphylactoid shock, assessed to be related to injection of gadobutrol. The contrast quality of gadobutrolenhanced images was rated by treating physicians as good or excellent in $97 \%$ cases, with similar ratings in all patient subgroups and indications.

Conclusions The GARDIAN study shows that gadobutrol at the recommended dose is well tolerated across a large, diverse patient population.

Key points

- Gadobutrol at recommended dose shows low rates of adverse drug reactions

- Gadobutrol demonstrates a uniform safety profile across diverse patient groups

- Gadobutrol provides excellent contrast quality in routine practice

7 Department of Radiology, General Hospital of Shenyang Military Region, Shenyang, China

8 Department of Radiology, Tangshan Worker's Hospital, Tangshan, China

9 Department of Radiology, Third Affiliated Hospital of Sun Yat-Sen University, Guangzhou, China

10 Department of Radiology and Medical Imaging, National Taiwan University, Medical College and Hospital, Taipei, Taiwan

11 Department of Radiology, Tri-Service General Hospital, National Defense Medical Center, Taipei, Taiwan

12 Department of Radiology, Taipei Veterans General Hospital, Taipei, Taiwan

13 Medical \& Clinical Affairs Radiology, Bayer Pharmaceutical Division, Berlin, Germany

14 Department of Radiology, Columbia College of Physicians and Surgeons, New York, NY 10021, USA 
Keywords Adverse drug reaction - Contrast media . Gadobutrol $\cdot$ Magnetic resonance imaging $\cdot$ Safety practice, including the age group 2 to 7 years as well as patients with renal impairment or cardiac disease and patients considered at risk for contrast media $(\mathrm{CM})$ reactions.

\section{Methods}

\section{Trial design}

GARDIAN was a phase IV, non-interventional, prospective, multicentre, post-authorization safety study (PASS). The study was conducted between August 2010 and April 2013 at 272 study centres in 17 countries in Africa, Asia, Europe, and North America (NCT01095081). The study protocol was approved by local ethics committees/institutional review boards at the respective study sites and was conducted in accordance with ethical principles consistent with the Declaration of Helsinki and the International Conference of Harmonisation guidelines, Good Clinical Practice (ICHGCP). The study adhered to guidelines of the EMA, the US Food and Drug Administration (FDA) [16, 17], local laws and regulations. Each patient provided written informed consent prior to study enrolment.

\section{Participants}

Male or female adults and children who were scheduled to undergo cranial or spinal MRI, liver or kidney MRI or MRA with gadobutrol enhancement were eligible for enrolment. There were no exclusion criteria beyond the contraindications in the Summary of Product Characteristics for Gadovist (i.e. hypersensitivity to the active substance or to any of the excipients).

Patients received medicinal products according to standard clinical practice, with no additional diagnostic or monitoring processes as a result of study participation. Patients with moderate or severe renal impairment (estimated glomerular filtration rate [eGFR] $30-59$ and $<30 \mathrm{~mL} / \mathrm{min} / 1.73 \mathrm{~m}^{2}$, respectively) were scheduled for follow-up investigation after 3 months, at the discretion of the treating physician and in accordance with routine practice. Any skin reactions suggestive of NSF were compulsorily followed up as potential AEs.

\section{Outcome measures}

Patient demographics, medical data (concomitant diseases and treatments), contrast agent risk factors (including previous $\mathrm{CM}$ reactions), as well as any signs and symptoms or treatments administered for contrast reactions were documented by the treating physician or nurse in case report forms at the time of MRI. Information on the CM intravenous injection (dose, amount) and subjective assessment of contrastenhanced image quality were also recorded. 
The primary study endpoint was the overall incidence of adverse drug reactions (ADRs) and serious adverse events (SAEs) following gadobutrol administration, including the rates, severity, and symptoms of events. Adverse events (AEs) documented by the treating physician or nurse were categorized as ADRs based on the judgment of the treating physician. SAEs were defined as events that are medically important, life-threatening, fatal, or involved hospitalization or prolongation of current hospitalization, disability/incapacity, or birth defects.

Secondary study endpoints were the rates, quality, and symptoms of AEs and ADRs associated with gadobutrol in special patient groups, including patients at risk for any CM reaction (i.e. with previous $\mathrm{CM}$ reactions, allergies, or bronchial asthma), patients with renal impairment or cardiac disease and patients aged $<18$ years. ADR rates were analysed with respect to the gadobutrol dose administered, geographic region and medical indication. Additionally, the image quality was rated subjectively by investigators on a four-point scale (poor, moderate, good, or excellent).

\section{Statistical analyses}

Descriptive analyses were performed on continuous and categorical data. Continuous data were described by median, mean, standard deviation, maxima, and minima, as well as upper and lower quartiles. Categorical data were presented in frequency tables. Safety and tolerability was assessed by reports of AEs, summarized using the Medical Dictionary for Regulatory Activities (MedDRA) coding system (version 13.0) and categorized by relationship, seriousness, and outcome. Event rates for AEs/ADRs in patients were calculated as a proportion of the study population. Analyses were performed on the total study population (pooled analysis) and in at-risk patient subgroups. Geographic regions were analysed by pooling countries into three groups: Asia, Europe, and "Other" (Canada and South Africa).

Safety analyses were performed on the safety population, which included all subjects assigned to treatment who received at least one dose of gadobutrol. The efficacy population included all subjects who underwent MRI/ MRA scans with gadobutrol injection. Statistical analyses were performed using the software package SAS version 9.2 (SAS Institute, Cary, NC, USA). Significance tests ( $\chi^{2}$-test and Fisher's exact test) were performed to investigate differences in the occurrence of ADRs according to gender and regions.

As a post-approval commitment with the EMA, a study population of at least 20,000 patients from approximately 200 sites in Europe and Asia was planned, including at least 600 patients aged $<18$ years (paediatric population) with at least 100 patients aged 2 to 6 years.

\section{Results}

\section{Baseline demographics}

A total of 23,775 eligible patients were enrolled in the GARDIAN study. Of those, 23,708 patients were administered at least one dose of gadobutrol and were included

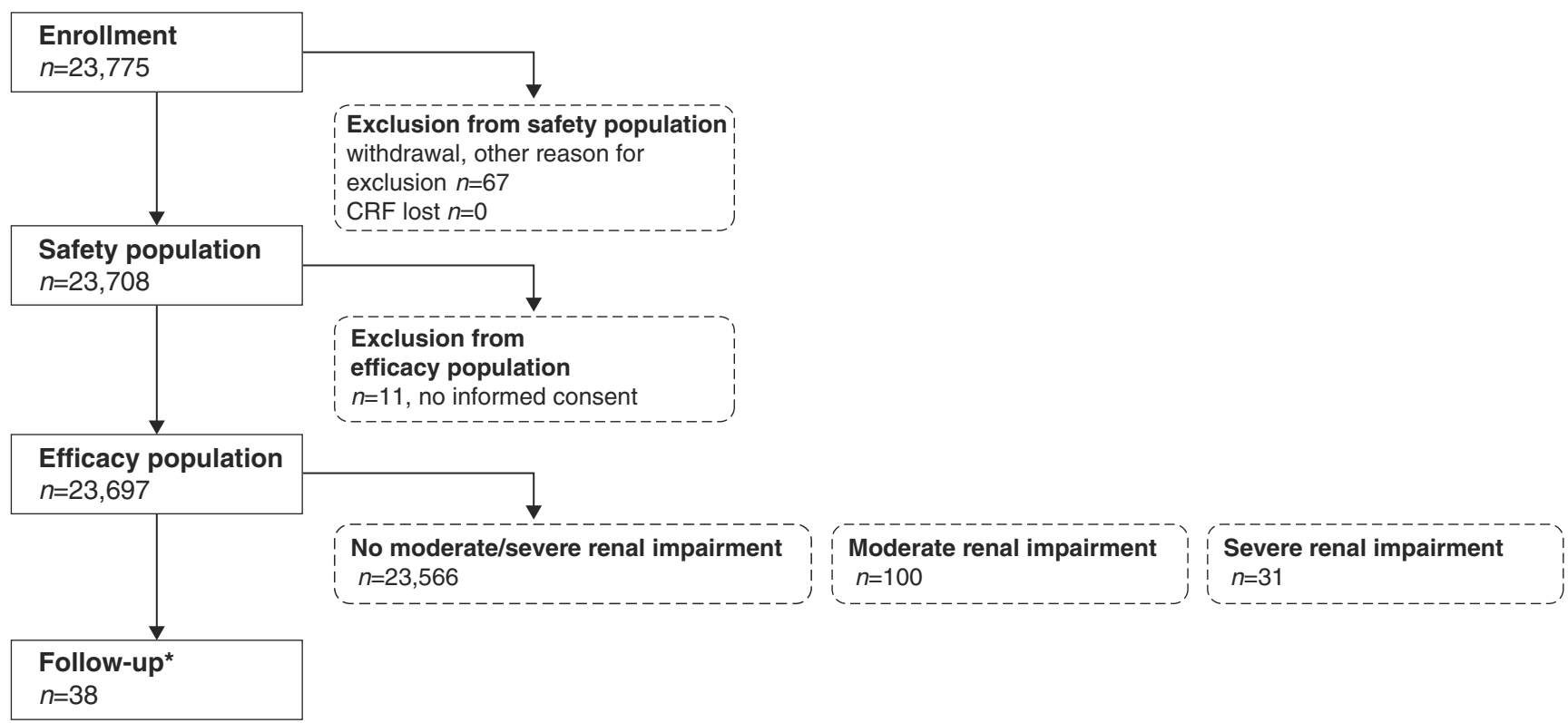

*11 patients with renal impairment

Fig. 1 Disposition of patients. $C R F$ case report form 
Table 1 Number of adult and paediatric patients per country (safety population)

\begin{tabular}{llll}
\hline Country & Adult & Paediatric & $\begin{array}{l}\text { Total } \\
(n, \% \text { by region })\end{array}$ \\
\hline Asia & & & $16,610(70 \%)$ \\
China & 4,843 & 156 & $4,999(30.1)$ \\
Kazakhstan \& Kyrgyzstan & 2,475 & 144 & $2,619(15.8)$ \\
Korea & 6,126 & 108 & $6,234(37.5)$ \\
Taiwan & 2,667 & 16 & $2,683(16.2)$ \\
Thailand & 74 & 1 & $75(0.5)$ \\
Europe & & & $6,831(29 \%)$ \\
Bosnia \& Herzegovina & 418 & 28 & $446(6.5)$ \\
Czech Republic & 598 & 6 & $604(8.8)$ \\
France & 1,041 & 9 & $1,050(15.4)$ \\
Germany & 1 & 465 & $466(6.8)$ \\
Greece & 201 & 8 & $209(3.1)$ \\
Hungary & 297 & 2 & $299(4.4)$ \\
Italy & 572 & 17 & $589(8.6)$ \\
Russia & 1,950 & 101 & $2,051(30.0)$ \\
$\quad$ Spain & 1,103 & 14 & $1,117(16.4)$ \\
Other region & & & $267(1 \%)$ \\
Canada & 67 & 63 & $130(48.7)$ \\
South Africa & 133 & 4 & $137(51.3)$ \\
\hline
\end{tabular}

in the safety population (Fig. 1). This patient population consisted of approximately two thirds Asian $(n=15,923)$ and one third white/Caucasian $(n=7,459)$ patients. Patient recruitment by country is shown in Table 1 . Approximately one half of patients $(48.2 \%)$ were male; median age was 52 years, with median height, weight, and body mass index at $165 \mathrm{~cm}, 65 \mathrm{~kg}$, and $23.8 \mathrm{~kg} / \mathrm{m}^{2}$, respectively (Table 2).

A total of 1,060 patients ( $4.5 \%$ ) presented with at least one risk factor for $\mathrm{CM}$ reaction, including a previous $\mathrm{CM}$ reaction $(n=105)$, allergies $(n=833)$, or bronchial asthma $(n=253)$. Some patients were enrolled at the discretion of the treating physician due to the following: 1,233 patients $(5.2 \%)$ had concomitant cardiac diseases, and 153 patients $(0.6 \%)$ had renal impairment, with 17 patients receiving dialysis. Of the patients with renal impairment, 15 had mild (eGFR 60$90 \mathrm{~mL} / \mathrm{min} / 1.73 \mathrm{~m}^{2}$ ), 100 moderate (eGFR $<60$ but $>30 \mathrm{~mL} /$ $\min / 1.73 \mathrm{~m}^{2}$ ), and 31 severe renal impairment (eGFR $<30 \mathrm{~mL} / \mathrm{min} / 1.73 \mathrm{~m}^{2}$ ); eGFR was unavailable for seven renal impairment patients. Eleven follow-up investigations were documented in patients with renal impairment, at a median of $95( \pm 9)$ days from the time of MRI/MRA. A total of $1,142(4.8 \%)$ paediatric patients were included in the safety population, most aged 7 to $<18$ years $(84.9 \%)$. Detailed results for the paediatric population will be reported elsewhere.

Eleven patients were excluded from the study because they did not provide informed consent or receive an MRI/MRA scan; therefore, 23,697 patients were valid for the efficacy population (Fig. 1).
Table 2 Demographics and baseline characteristics of the study population (safety population)

\begin{tabular}{lll}
\hline Demographic data & & $\begin{array}{l}N(\% \text { by total } \\
\text { patients })\end{array}$ \\
\hline Total patients & & 23,708 \\
Gender & Male & $11,429(48.2)$ \\
& Female & $12,266(51.7)$ \\
Age groups (years) & Median & 51.9 \\
& $<18$ & $1,142(4.8)$ \\
& $18-<45$ & $7,180(30.3)$ \\
& $45-<65$ & $10,524(44.4)$ \\
& $65-<80$ & $4,330(18.3)$ \\
Height & $\geq 80$ & $526(2.2)$ \\
(median, cm) & & 165 \\
Body weight & & \\
(median, kg) & & 65 \\
BMI & & \\
kg/m ${ }^{2}$ ) & & 23.8 \\
At least one CM risk factor & Total & $1,060(4.5)$ \\
& Male & $387(3.4)$ \\
Types of risk factor for CM & Female & $673(5.5)$ \\
reaction & Previous CM & $105(0.4)$ \\
& reaction & $833(3.5)$ \\
Cardiac concomitant disease & Allergies & $253(1.1)$ \\
Renal impairment & & $1,233(5.2)$ \\
\hline & & $153(0.6)$ \\
\hline Asthma &
\end{tabular}

$B M I$ body mass index; $C M$ contrast media

\section{MRI indications}

The majority of MRI scans in the 23,697 patients in the efficacy population were for suspected tumours $(54.4 \%)$, followed by infarction $(9.0 \%)$, inflammatory disease $(6.3 \%)$, staging $(3.9 \%)$, multiple sclerosis $(3.5 \%)$, trauma (2.8\%), and other indications (19.8\%); data were unavailable for 52 patients $(0.2 \%)$. Investigations included MRI in 16,210 patients and MRA in 7,269 patients. The central nervous system was investigated in $62.3 \%$, the vessels and MRA in $30.7 \%$, the liver in $7.4 \%$ and kidneys in $1.6 \%$. The majority of the 7,269 MRA investigations were applied to the head (59.0\%) or neck $(19.1 \%)$. Since MRA and MRI were often performed together, 1,923 patients $(8.1 \%)$ had more than one investigation type.

\section{Gadobutrol dose}

The median dose of gadobutrol administered was $0.11 \mathrm{mmol} /$ $\mathrm{kg} \mathrm{BW}$, with more than half the patients $(55.7 \%)$ receiving a dose $0.1-0.2 \mathrm{mmol} / \mathrm{kg} \mathrm{BW}$ (Table 4). Doses $>0.3 \mathrm{mmol} / \mathrm{kg}$ BW $(0.4 \%$ of patients) were used according to the clinical assessment by the treating physician. Rates of administration of doses $>0.3 \mathrm{mmol} / \mathrm{kg}$ BW were similar in at-risk and cardiac disease subgroups $(0.1-0.5 \%)$, while no patients with renal 
Table 3 ADRs and non-drugrelated $\mathrm{AE}$ incidences, categorized by system organ class (safety population)

\begin{tabular}{|c|c|c|c|c|c|}
\hline System organ class & $\mathrm{AE}$ term & $\begin{array}{l}\text { ADRs } \\
(N)\end{array}$ & $\begin{array}{l}\text { ADR incidence } \\
(\%)\end{array}$ & $\begin{array}{l}\text { Non-ADR } \\
\text { AEs }(N)\end{array}$ & $\begin{array}{l}\text { Non-ADR AE } \\
\text { incidence }(\%)\end{array}$ \\
\hline \multirow[t]{3}{*}{ GI disorders } & Nausea $^{\mathrm{a}}$ & 65 & 0.27 & 3 & 0.01 \\
\hline & Vomiting & 23 & 0.10 & 12 & 0.05 \\
\hline & Salivary hypersecretion & 2 & 0.01 & 0 & 0.00 \\
\hline \multirow{3}{*}{$\begin{array}{l}\text { Nervous system } \\
\text { disorders }\end{array}$} & Dizziness & 23 & 0.10 & 4 & 0.02 \\
\hline & Headache & 3 & 0.01 & 2 & 0.01 \\
\hline & Dysgeusia & 2 & 0.01 & 0 & 0.00 \\
\hline \multirow{3}{*}{$\begin{array}{l}\text { General disorders } \\
\text { and administration } \\
\text { site conditions }\end{array}$} & $\begin{array}{l}\text { Injection-site } \\
\text { reaction }\end{array}$ & 9 & 0.04 & 1 & 0.00 \\
\hline & Feeling hot & 7 & 0.03 & 0 & 0.00 \\
\hline & Chest discomfort & 3 & 0.01 & 0 & 0.00 \\
\hline \multirow{4}{*}{$\begin{array}{l}\text { Skin and subcutaneous } \\
\text { tissue disorders }\end{array}$} & Rash & 8 & 0.03 & 0 & 0.00 \\
\hline & Pruritus & 7 & 0.03 & 0 & 0.00 \\
\hline & Urticaria & 7 & 0.03 & 2 & 0.01 \\
\hline & Erythema & 2 & 0.01 & 0 & 0.00 \\
\hline \multirow{3}{*}{$\begin{array}{l}\text { Respiratory, thoracic, } \\
\text { and mediastinal } \\
\text { disorders }\end{array}$} & Dyspnoea $^{\mathrm{b}}$ & 6 & 0.03 & 1 & 0.00 \\
\hline & Throat irritation & 3 & 0.01 & 0 & 0.00 \\
\hline & Cough & 2 & 0.01 & 0 & 0.00 \\
\hline Cardiac disorders & Tachycardia & 2 & 0.01 & 0 & 0.00 \\
\hline Eye disorders & Eyelid oedema & 2 & 0.01 & 0 & 0.00 \\
\hline Vascular disorders & Flushing & 2 & 0.01 & 0 & 0.00 \\
\hline
\end{tabular}

${ }^{\mathrm{a}}$ One patient had two AEs (nausea and vomiting); ${ }^{\mathrm{b}} 24 \mathrm{~h}$ after CM administration

$A D R$ adverse drug reaction; $A E$ adverse event; $C M$ contrast media; $G I$ gastrointestinal impairment received these doses. The median injection rate of gadobutrol was $1.5 \mathrm{~mL} / \mathrm{s}$, and an automatic injector was used in $29 \%$ cases.

\section{Adverse events (primary endpoint)}

\section{All patients}

Of 23,708 patients in the safety population, $202(0.9 \%)$ reported 251 AEs, with a maximum reported intensity of mild in most cases $(84.9 \%)$, followed by moderate $(12.0 \%)$ and severe $(2.4 \%)$ reported intensity. Onset of AEs occurred within 5 min after gadobutrol injection in $62 \%$ of patients (median: $3.5 \mathrm{~min}$ ) or within the next $24 \mathrm{~h}(35.5 \%)$. No treatment action was taken for the majority of AEs $(75 \%)$ and events resolved in $94 \%$ of cases; in the remainder, outcome was unknown or missing in $4.8 \%$, and recovering/resolving in $0.4 \%$. There were two events with fatal outcome in the study population (please see below.)

For these 251 AEs, 215 were categorized as ADRs occurring in $170(0.7 \%)$ patients. The maximum reported intensity of ADRs was mild in most cases (83.6\%), with remaining events categorized as moderate $(13.2 \%)$ or severe $(2.3 \%)$. The most commonly documented ADR was nausea $(0.3 \%)$, followed by vomiting $(0.1 \%)$ and dizziness $(0.1 \%)$ (Table 3$)$. ADR rates were $0.9 \%$ in females and $0.6 \%$ in males $(p=0.0013$, Fisher's exact test). There were no differences in ADR rates according to dose of gadobutrol (Table 4).

Five of the 202 patients with AEs ( $0.02 \%)$ experienced an SAE, with events in four patients considered as ADRs by the treating physician (Table 5). One patient experienced a fatal anaphylactoid shock. This patient was 76 years old, female, and received $7.5 \mathrm{~mL}$ gadobutrol. After MRI, the patient developed signs of anaphylaxis, reported as dizziness and cyanosis, and was taken to the emergency room, where she also developed signs of pulmonary oedema. The event was

Table 4 ADR incidence according to gadobutrol dose groups (mmol/kg) (safety population)

\begin{tabular}{lll}
\hline $\begin{array}{l}\text { Gadobutrol dose group } \\
(\mathrm{mmol} / \mathrm{kg} \mathrm{BW})\end{array}$ & Number (\%) of patients $\mathrm{a}^{\mathrm{a}}$ & $\begin{array}{l}\text { ADR incidence } \\
(\%)\end{array}$ \\
\hline Mean dose $=0.12$ & \\
Median dose $=0.11$ & $8,696(36.7)$ & 0.61 \\
$\leq 0.1$ & $13,207(55.7)$ & 0.78 \\
$>0.1-0.2$ & $1,692(7.1)$ & 0.83 \\
$>0.2-0.3$ & $101(0.4)$ & 0 \\
$>0.3$ & & \\
\hline
\end{tabular}

${ }^{\mathrm{a}}$ Information missing for 12 patients $(0.05 \%)$

$A D R$ adverse drug reaction; $B W$ body weight 
Table 5 Serious AEs and serious ADRs in individual patients: gadobutrol dose, relationship to study, and severity

\begin{tabular}{lllll}
\hline Patient & SAE/SADR & $\begin{array}{l}\text { Dose } \\
(\mathrm{mmol} \mathrm{Gd} / \mathrm{kg} \mathrm{BW})\end{array}$ & Relationship & Severity \\
\hline A & Cardiac arrest & & \\
B & Nausea & $>0.1-0.2$ & Not related & Fatal \\
B & Dyspnoea & $\leq 0.1$ & Related & Moderate \\
B & Laryngeal stenosis & $\leq 0.1$ & Related & Moderate \\
C & Anaphylactic shock & $\leq 0.1$ & Related & Moderate \\
D & Pulse pressure decreased & $>0.1-0.2$ & Related & Fatal \\
D & Unresponsive to stimuli & $>0.1-0.2$ & Related & Severe \\
D & Hypotension & $>0.1-0.2$ & Related & Severe \\
E & Seizure & $>0.1-0.2$ & Related & Severe \\
\hline
\end{tabular}

${ }^{a}$ This cardiac arrest occurred 6 months after gadobutrol administration; ${ }^{\mathrm{b}}$ This patient with existing seizure disorder due to glioblastoma on medication had a breakthrough seizure

$A E$ adverse event; $A D R$ adverse drug reaction; $B W$ body weight; $S A D R$ serious ADR.

assessed as anaphylactic shock related to the administration of gadobutrol. A second death, unrelated to the study drug, was reported at least 6 months after the end of study as a result of progression of glioblastoma. The other three SAEs resolved after 10-20 min; one patient experienced a transient weak pulse and hypotension, one patient had breakthrough of epilepsy and one patient had transient laryngeal constriction, dyspnoea and nausea.

\section{At-risk patient populations}

In the 1,060 patients assessed to be at risk for a $\mathrm{CM}$ reaction, $32(3.0 \%)$ patients experienced at least one AE, including $27(2.5 \%)$ patients determined by the treating physician to have an ADR. One patient $(0.1 \%)$ experienced an epileptic episode (grand mal convulsion), which resolved after $10 \mathrm{~min}$; this was a breakthrough of the disease under investigation and was assessed to be serious and drugrelated (described above).

One $\operatorname{AE}(0.7 \%)$ and no ADRs were reported by the 153 patients with renal impairment. The AE was a cardiac arrest occurring 86 days after gadobutrol administration, and was rated as serious but not related to gadobutrol injection. No skin reactions suggestive of NSF were reported in any patient including patients with renal impairment. Among 11 patients with renal impairment followed up after 3 months, there was one case report of skinrelated signs or symptoms (i.e. "burning or itching"), which the patient reported as a routine posthaemodialysis symptom. This patient had no musculoskeletal or other symptoms suggestive of NSF. The patient had presented with acute renal impairment prior to MR examination, but had recovered at follow-up (serum creatinine $=0.68 \mathrm{mg} / \mathrm{dL}$ ). Of 1,233 patients with cardiac disease, $14(1.1 \%)$ had at least one AE, including 11 patients $(0.9 \%)$ with an ADR, all non-cardiac in type.

\section{Paediatric population}

Eight out of 1,142 $(0.7 \%)$ paediatric patients reported at least one AE, including $6(0.5 \%)$ patients experiencing an ADR. No SAEs were reported in the paediatric population.

\section{Geographic regions}

The proportions of patients experiencing AEs in different geographic regions were: Asia $0.7 \%$ (ratio 1:135), Europe $1.1 \%$ (1:88), and Other $0.4 \%$ (1:127) $\left(p=0.007, \chi^{2}\right.$-test). Similarly, the proportions of patients experiencing ADRs by region were: Asia $0.6 \%$ (1:158), Europe $0.9 \%$ (1:107), and Other $0.4 \%$ (1:267). Comparisons of the most common AEs in the different regions are shown in Table 6 . Of the four patients who experienced a drug-related SAE, two were from Asia

Table 6 Incidences of common AE ( $>5$ patients in any group), categorized by region (safety population)

\begin{tabular}{|c|c|c|c|c|c|c|c|}
\hline \multirow[t]{3}{*}{ System organ class } & \multirow{2}{*}{\multicolumn{2}{|c|}{$\frac{\text { Asia }}{N=16,610}$}} & \multirow{2}{*}{\multicolumn{2}{|c|}{$\frac{\text { Europe }}{N=6,831}$}} & \multirow{2}{*}{\multicolumn{2}{|c|}{$\frac{\text { Other }}{N=267}$}} & \multirow[t]{3}{*}{$p$-value } \\
\hline & & & & & & & \\
\hline & $n$ & $\%$ & $n$ & $\%$ & $n$ & $\%$ & \\
\hline Any AE & 123 & 0.74 & 78 & 1.14 & 1 & 0.37 & $0.007^{\mathrm{a}}$ \\
\hline Nausea & 38 & 0.23 & 30 & 0.44 & 0 & 0 & $0.016^{\mathrm{a}}$ \\
\hline Vomiting & 28 & 0.17 & 7 & 0.10 & 0 & 0 & $0.4^{\mathrm{a}}$ \\
\hline Dizziness & 23 & 0.14 & 4 & 0.06 & 0 & 0 & $0.22^{\mathrm{a}}$ \\
\hline Urticaria & 7 & 0.04 & 2 & 0.03 & 0 & 0 & $1.0^{\mathrm{b}}$ \\
\hline Injection-site reaction & 6 & 0.04 & 4 & 0.06 & 0 & 0 & $0.55^{\mathrm{b}}$ \\
\hline Rash & 6 & 0.04 & 2 & 0.03 & 0 & 0 & $1.0^{\mathrm{b}}$ \\
\hline
\end{tabular}


$(<0.1 \%)$ and one each from Europe $(<0.1 \%)$ and Other region $(0.4 \%)$.

\section{Medical indications}

No relationship was found between the likelihood of an AE, SAE, or ADR and specific medical indications (data not presented).

\section{Contrast quality}

The contrast quality of gadobutrol was evaluated by treating physicians as good or excellent in the majority of cases (97\%), with similar efficacy outcomes in the subgroup populations: patients at risk for CM reactions $(98 \%)$ and patients with renal impairment (99\%) or cardiac disease (97\%). For all medical indications, contrast quality was rated as good or excellent in $97 \%$ of cases, including infarction (96.6\%), inflammatory disease $(96.6 \%)$, intracerebral haemorrhage (99.4\%), multiple sclerosis (98.9\%), staging (95.7\%), subarachnoid haemorrhage $(99.5 \%)$, trauma (93.9\%), and tumour $(97.3 \%)$. Examples of gadobutrol-enhanced MRA images in a patient enrolled in GARDIAN are shown in Fig. 2.

\section{Discussion}

This prospective, non-interventional study provides the largest analysis of safety and tolerability of gadobutrol, a macrocyclic, non-ionic MRI contrast agent, in routine clinical practice. Gadobutrol at a median dose of $0.11 \mathrm{mmol} / \mathrm{kg}$ BW was well tolerated, with a favourable safety profile in diverse patient populations, geographic regions, and dose groups. The contrast quality of gadobutrol-enhanced images was good or excellent in $97 \%$ of cases and in at least $94 \%$ for all patient subgroups and indications.

The low incidence of ADRs in GARDIAN (0.7 \%) is consistent with a previous analysis of gadobutrol (Table 7). In that analysis, which included 14,299 patients from six post- marketing observational surveillance studies conducted in Europe and Canada, the ADR rate was $0.55 \%$ at a mean gadobutrol dose of $0.16 \mathrm{mmol} / \mathrm{kg} \mathrm{BW}$ [13]. Another analysis of 4,549 patients from 34 clinical trials reported a higher ADR incidence rate of $4.0 \%$ [14], which can be attributed to the different methodology of data collection in randomized controlled clinical trials - including, for example, a longer followup duration (from $24 \mathrm{~h}$ to 7 days after gadobutrol administration) than in the current study, which followed routine clinical practice. Generally similar ADR rates have been reported for other GBCAs (Table 7) [13, 14, 18-22].

GARDIAN included an assessment of the safety of gadobutrol in at-risk populations not previously studied in routine clinical practice. Patients at-risk for a $\mathrm{CM}$ reaction (i.e. with a previous $\mathrm{CM}$ reaction, allergy, asthma) experienced ADRs at an incidence of $2.5 \%$. The incidence of ADRs in patients with renal impairment $(0.0 \%)$ or cardiac disease $(0.9 \%)$ and for paediatric patients $(0.5 \%)$ was comparable with the total population $(0.7 \%)$, and showed no relationship with gadobutrol dose. Other analyses of gadobutrol studies (referred to above) found no consistent relationship between $\mathrm{AE}$ incidence and degree of impairment in renal function or cardiac disorders [14]. Similarly, no impact of gadobutrol dose on rate of AE incidences was found in these at-risk populations [14]. However, the existing consensus based on prior evidence is that renal patients are at elevated risk of certain AEs. Reactions to contrast agents - iodinated as well as gadolinium-based contrast agents - can be categorized by their pathophysiology into allergy-like, mostly dose-independent and potentially organotoxic, dose-dependent reactions [23]. At the dose level used in contrast-enhanced MRI, the likelihood of observing dosedependent acute reactions can be considered to be very low.

A boxed warning relating to risk of NSF is included in the prescribing information at the request of the US Food and Drug Administration in patients with impaired elimination of GBCAs, including gadobutrol [24]. While case reports have described individuals who developed NSF following exposure to gadobutrol, confounders were present in these cases that may have contributed to NSF development [25-27].
Fig. 2 Gadobutrol-enhanced magnetic resonance angiography (MRA) of the head and neck region, including carotid and intracranial vessels, scanned with 1.5 Tesla MRI scanner: 50-yearold male with frequent headaches but no abnormal findings; MR angiography in coronal views of early arterial (a) and late arterial (b) phases and (c) delayed phase of MR venography
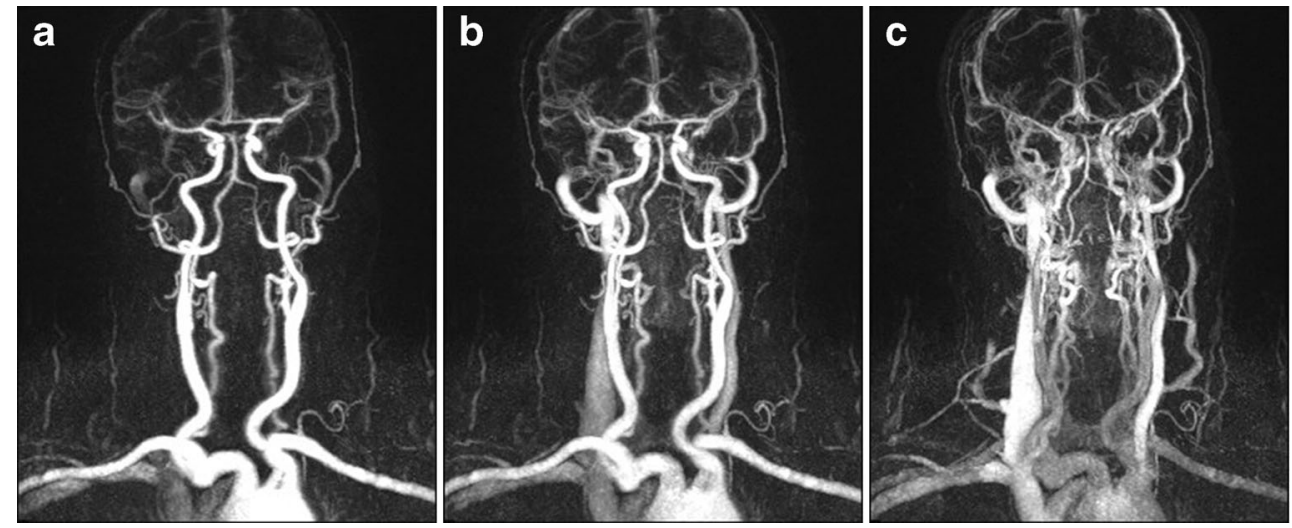
Table 7 Comparison of ADRs: gadobutrol versus other GBCAs

\begin{tabular}{|c|c|c|c|c|c|c|c|c|}
\hline Study Design & $\begin{array}{l}\text { Gadobutrol }^{\mathrm{a}} \\
(N=23,708) \\
\text { Prospective }\end{array}$ & $\begin{array}{l}\text { Gadobutrol [14] } \\
(N=4,549) \\
\begin{array}{l}\text { Data collection from } \\
\text { randomized controlled } \\
\text { trials }\end{array}\end{array}$ & $\begin{array}{l}\text { Gadobutrol } \\
{[13]} \\
(N=14,299) \\
\text { Surveillance }\end{array}$ & $\begin{array}{l}\text { Gadopentetate } \\
\text { dimeglumine } \\
{[20]} \\
(N=15,496) \\
\text { Surveillance }\end{array}$ & $\begin{array}{l}\text { Gadoterate } \\
\text { meglumine } \\
{[19]} \\
(N=24,308) \\
\text { Surveillance }\end{array}$ & $\begin{array}{l}\text { Gadobenate } \\
\text { dimeglumine } \\
{[18]} \\
(N=23,553) \\
\text { Surveillance }\end{array}$ & $\begin{array}{l}\text { Gadoterate } \\
\text { meglumine } \\
{[21]} \\
(N=84,621) \\
\text { Surveillance }\end{array}$ & $\begin{array}{l}\text { Gadoterate } \\
\text { meglumine } \\
{[22]} \\
(N=3,444) \\
\text { Surveillance }\end{array}$ \\
\hline $\begin{array}{l}\text { Mean dose } \\
(\mathrm{mmol} / \mathrm{kg} \mathrm{BW}) \\
\text { ADR }(\%)\end{array}$ & 0.12 & NA & 0.16 & 0.1 & 0.11 & NA & 0.11 & 0.22 \\
\hline Overall rates & 0.7 & 4.0 & 0.55 & 2.4 & 0.4 & 0.76 & 0.34 & 0.93 \\
\hline Nausea/vomiting & 0.37 & 1.6 & 0.31 & 0.61 & 0.23 & 0.55 & 0.3 & 0.50 \\
\hline Heat/warmth & 0.03 & 0.5 & 0.04 & - & 0.02 & - & $<0.1$ & - \\
\hline Headache & 0.01 & 1.5 & 0.01 & 0.44 & - & - & - & - \\
\hline Paraesthesia & - & 0.1 & 0.01 & 0.17 & 0.02 & 0.004 & $<0.1$ & - \\
\hline Dizziness & 0.10 & 0.4 & 0.02 & 0.19 & - & - & $<0.1$ & - \\
\hline $\begin{array}{l}\text { Focal } \\
\text { convulsions }\end{array}$ & $<0.01$ & - & - & - & - & - & - & - \\
\hline Urticaria & 0.03 & - & 0.08 & 0.07 & 0.02 & 0.15 & $<0.1$ & 0.06 \\
\hline $\begin{array}{l}\text { Other allergic- } \\
\text { like skin } \\
\text { reactions }\end{array}$ & 0.01 & - & 0.07 & 0.09 & - & - & - & 0.03 \\
\hline $\begin{array}{l}\text { Allergic-like } \\
\text { mucosal } \\
\text { reactions }\end{array}$ & $<0.01$ & - & 0.07 & - & - & - & - & - \\
\hline $\begin{array}{l}\text { Flush/ } \\
\text { vasodilation }\end{array}$ & 0.01 & - & 0.01 & 0.07 & - & - & - & - \\
\hline $\begin{array}{l}\text { Cardiovascular } \\
\text { reactions }\end{array}$ & 0.01 & - & 0.05 & - & - & - & - & 0.03 \\
\hline $\begin{array}{r}\text { Tachycardia, } \\
\text { arrhythmia }\end{array}$ & 0.01 & - & 0.04 & - & - & - & - & - \\
\hline Other symptoms & $0.35^{\mathrm{b}}$ & $>0.0-0.6^{\mathrm{c}}$ & $0.2^{\mathrm{d}}$ & - & $0.1^{\mathrm{e}}$ & $0.13^{\mathrm{f}}$ & $0.06^{\mathrm{g}}$ & $0.17^{\mathrm{h}}$ \\
\hline
\end{tabular}

${ }^{\text {a }}$ Current study. Includes at-risk population, $n=1,060(4.5 \%)$

b Includes rash, pruritus, dyspnoea, chest discomfort, injection site-related symptoms, throat irritation, eyelid oedema, salivary hypersecretion, dysgeusia, cough, erythema, and other ADRs that occurred with a frequency of $<0.01 \%$

${ }^{c}$ Includes other ADRs that occurred with a frequency of $\geq 0.1 \%$ : injection site reaction, dysgeusia, rash, pruritus, erythema, dyspnoea; $0.1 \%$ : hypersensitivity/anaphylactoid reaction, loss of consciousness, convulsion, parosmia, tachycardia, palpitation, dry mouth, malaise, and feeling cold

${ }^{\mathrm{d}}$ Includes anaphylactic reaction, itching, throat swelling/sore, cough/dyspnoea, hypersalivation, lip swelling, sweating, hoarseness, and other symptoms

e Includes most frequently occurring AE of injection-site pain, pruritus, taste alteration, retching, coughing

${ }^{\mathrm{f}}$ Includes gagging, chest pain, dyspnoea, perioral and periorbital angioneurotic oedema, olfactory hallucinations, itchiness without hives, hypertensive crisis, sneezing, and loss of bowel control

g Includes pruritus, retching, sweating increased, taste alteration

${ }^{\mathrm{h}}$ Includes coughing, sneezing, abnormal liver function, drug eruption, abnormal sensation

$B W$, body weight; $A D R$, adverse drug reaction. Some patients may experience more than one AE symptom.

GARDIAN is the first large-scale, prospective study to evaluate the safety of gadobutrol in routine clinical practice, including at-risk patients, since the gadolinium-related risks for NSF were reported. Investigators found no NSF-related symptoms in the study patients, including patients with renal impairment who were followed up approximately 3 months later. This is consistent with retrospective analyses of gadobutrol use in renal impaired patients, which found no cases of NSF within a longer follow-up duration $[14,28]$. An ongoing prospective study (Safety of Gadovist in Renally Impaired
Patients, "GRIP"; NCT00828737) evaluating the safety of gadobutrol in patients with moderate to severe renal impairment over a 2-year follow up will further contribute to understanding the risk of NSF.

One case of fatal anaphylactic shock was assessed to be related to administration of gadobutrol. To place this event in perspective, pharmacovigilance data that included 12.67 million gadobutrol administrations reported 17 deaths possibly related to gadobutrol (1.34 deaths per million doses) [29]. This estimated death rate is within the range previously reported for GBCA use in the USA $(0.15-2.7$ deaths per million 
doses) [30]. These data indicate that lethal reactions to gadolinium-based contrast agents are very rare.

Further conclusions from the GARDIAN study are that the ADRs associated with gadobutrol used in the approved dose range are unrelated to dose or medical indication. Females had a slightly higher rate of ADRs than males $(0.9 \%$ versus $0.6 \%$ ), as reported previously for gadobutrol in a large review of patients from observational trials and which has been reported for other CM including iodinated agents $[13,31,32]$.

Limitations of GARDIAN include the potential for underreporting of AEs or ADRs that is typical of non-interventional studies, in particular for mild AEs and ADRs. In addition, standards for the monitoring and recognition of AEs and ADRs may have varied largely between centres. In the GARDIAN study, due to the non-interventional study design, the selection of patients to be included was solely at the discretion of the treating physicians. This might have led to some selection bias at the individual sites. The strengths of GARDIAN include the prospective design with a large population size enrolled from multiple centres, which helps overcome the potential bias encountered in AE reports from single-centre, single-indication studies. GARDIAN also addresses the limited research that has been performed to date on the safety of gadobutrol in Asian countries, as approximately two thirds of the study population were from this region. Since Asian patients have a lower average body mass index [33], they received a lower total gadobutrol dose following weight adjustment than European patients in GARDIAN. A statistically significant - but not, in our view, clinically relevant - difference in overall ADR incidence rates was reported across geographic regions in GARDIAN. Minor differences in rates of individual ADRs and AEs were also noted, which may be relevant to practice in different regions.

\section{Conclusions}

In the prospective, non-interventional GARDIAN study, gadobutrol administered at the recommended dose was very well tolerated and provided excellent contrast quality in a large, diverse patient population. Gadobutrol possessed a similar safety and tolerability profile in adults, patients with renal impairment or cardiac disease and children. Patients at risk for CM reaction had a higher incidence of ADRs than other groups, but without an increased incidence of SAEs.

\footnotetext{
Acknowledgments Bayer Pharmaceutical Division provided support in the design and conduct of the study and in the collection, management and analysis of the data. Editorial support for this manuscript was provided by Bill Wolvey of PAREXEL, which was funded by Bayer Pharmaceutical Division. Statistical support was provided by Dr. Christine Windemuth-Kieselbach, Head of Biometry, Alcedis $\mathrm{GmbH}$. The scientific guarantor of this publication is Dr Petra Palkowitsch. Dr
}

Martin Prince has a patent agreement with Bayer related to MR angiography

Dr Petra Palkowitsch is a full-time employee of Bayer Pharmaceutical Division. This study has received funding by Bayer Pharmaceutical Division. Institutional Review Board approval was obtained at each study site (272 study centres in 17 countries). Written informed consent was obtained from all subjects (patients) in this study.

Methodology: prospective, observational, multicentre study.

Open Access This article is distributed under the terms of the Creative Commons Attribution-NonCommercial 4.0 International License (http:// creativecommons.org/licenses/by-nc/4.0/), which permits any noncommercial use, distribution, and reproduction in any medium, provided you give appropriate credit to the original author(s) and the source, provide a link to the Creative Commons license, and indicate if changes were made.

\section{References}

1. American College of Radiology. ACR Manual on Contrast Media, 2015. American College of Radiology Web site. Available via: http://www.acr.org/Quality-Safety/Resources/Contrast-Manual. Accessed 18 Jan 2016

2. American College of Radiology. ACR-SPR Practice Guideline for the Performance and Interpretation of Pediatric Magnetic Resonance Imaging (MRI), 2014. American College of Radiology Web site. Available via: http://www.acr.org/ /media/ACR/Documents/PGTS/ guidelines/MRI_Pediatric.pdf. Accessed 18 Jan 2016

3. Port M, Corot C, Violas X, Robert P, Raynal I, Gagneur G (2005) How to compare the efficiency of albumin-bound and nonalbuminbound contrast agents in vivo: the concept of dynamic relaxivity. Investig Radiol 40:565-573

4. Rohrer M, Bauer H, Mintorovitch J, Requardt M, Weinmann HJ (2005) Comparison of magnetic properties of MRI contrast media solutions at different magnetic field strengths. Investig Radiol 40: 715-724

5. Hadizadeh DR, Von FM, Kukuk GM et al (2010) Contrast material for abdominal dynamic contrast-enhanced 3D MR angiography with parallel imaging: intraindividual equimolar comparison of a macrocyclic $1.0 \mathrm{M}$ gadolinium chelate and a linear ionic $0.5 \mathrm{M}$ gadolinium chelate. AJR Am J Roentgenol 194:821-829

6. Essig M, Shiroishi MS, Nguyen TB, et al (2013) Perfusion MRI: the five most frequently asked technical questions. AJR Am J Roentgenol 20024-20034

7. Staks T, Schuhmann-Giampieri G, Frenzel T, Weinmann HJ, Lange L, Platzek J (1994) Pharmacokinetics, dose proportionality, and tolerability of gadobutrol after single intravenous injection in healthy volunteers. Investig Radiol 29:709-715

8. Frenzel T, Lengsfeld P, Schirmer H, Hutter J, Weinmann HJ (2008) Stability of gadolinium-based magnetic resonance imaging contrast agents in human serum at 37 degrees C. Investig Radiol 43:817-828

9. Scott LJ (2013) Gadobutrol: a review of its use for contrastenhanced magnetic resonance imaging in adults and children. Clin Drug Investig 33:303-314

10. Thomsen HS, Morcos SK, Almen T et al (2013) Nephrogenic systemic fibrosis and gadolinium-based contrast media: updated ESUR Contrast Medium Safety Committee guidelines. Eur Radiol 23: 307-318

11. European Medicines Agency. European Medicines Agency makes recommendations to minimise risk of nephrogenic systemic fibrosis with gadolinium-containing contrast agents. EMEA press office, 2009. Available via: http://www.ema.europa.eu/ema/index.jsp? 
curl=pages/news_and_events/news/2009/11/news_detail_000408. jsp\&mid=WC0b01ac058004d5c1. Accessed 18 Jan 2016

12. American College of Radiology. ACR Manual on Contrast Media: Nephrogenic Systemic Fibrosis, pp. 83-91, 2015. Available via: http://www.acr.org/quality-safety/resources/ /media/ 37D84428BF1D4E1B9A3A2918DA9E27A3.pdf/. Accessed 18 Jan 2016

13. Forsting M, Palkowitsch P (2010) Prevalence of acute adverse reactions to gadobutrol-a highly concentrated macrocyclic gadolinium chelate: review of 14,299 patients from observational trials. Eur J Radiol 74:e186-e192

14. Voth M, Rosenberg M, Breuer J (2011) Safety of gadobutrol, a new generation of contrast agents: experience from clinical trials and postmarketing surveillance. Investig Radiol 46:663-671

15. Kunze C, Mentzel HJ, Krishnamurthy R, Fleck R et al (2016) Pharmacokinetics and safety of macrocyclic gadobutrol in children aged younger than 2 years including term newborns in comparison to older populations. Investig Radiol 51:50-57

16. European Medicines Agency. ICH Topic E 8. General Considerations for Clinical Trials. (CPMP/ICH/291/95); March 1998. Available via: http://www.ema.europa.eu/docs/en GB/ document_library/Scientific guideline/2009/09/WC500002877. pdf. Accessed 18 Jan 2016

17. U.S. Department of Health and Human Services (1998) Guidance for Industry. E9 Statistical Principles for Clinical Trials; September 1998. Available via: http:/www.fda.gov/downloads/drugs/ guidancecomplianceregulatoryinformation/guidances/ucm073137. pdf. Accessed 18 Jan 2016

18. Nelson KL, Gifford LM, Lauber-Huber C, Gross CA, Lasser TA (1995) Clinical safety of gadopentetate dimeglumine. Radiology 196:439-443

19. Herborn CU, Honold E, Wolf M et al (2007) Clinical safety and diagnostic value of the gadolinium chelate gadoterate meglumine (Gd-DOTA). Investig Radiol 42:58-62

20. Bleicher AG, Kanal E (2008) Assessment of adverse reaction rates to a newly approved MRI contrast agent: review of 23,553 administrations of gadobenate dimeglumine. AJR Am J Roentgenol 191: W307-W311

21. Maurer M, Heine O, Wolf M, Durmus T, Wagner M, Hamm B (2012) Tolerability and diagnostic value of gadoteric acid in the general population and in patients with risk factors: results in more than 84,000 patients. Eur J Radiol 81:885-890
22. Ishiguchi T, Takahashi S (2010) Safety of gadoterate meglumine (Gd-DOTA) as a contrast agent for magnetic resonance imaging: results of a post-marketing surveillance study in Japan. Drugs R D 10:133-145

23. Sidhu PS, Dawson P (1999) Adverse reactions: cause, prophylaxis and management. In: Dawson P, Cosgrove DO, Grainger RG (eds) Textbook of contrast media. Isis Medical Media, Oxford, England

24. Peripheral \& Central Nervous System Drugs Advisory Committee. Briefing Document for Gadobutrol Injection NDA 201,277. FDA, 2011. Available via: http://www.fda.gov/downloads/ AdvisoryCommittees/CommitteesMeetingMaterials/Drugs/ PeripheralandCentralNervousSystemDrugsAdvisoryCommittee/ UCM240357.pdf. Accessed 18 Jan 2016

25. Wollanka H, Weidenmaier W, Giersig C (2009) NSF after gadovist exposure: a case report and hypothesis of NSF development. Nephrol Dial Transplant 24:3882-3884

26. Elmholdt TR, Jorgensen B, Ramsing M, Pedersen M, Braae Olesen A (2010) Two cases of nephrogenic systemic fibrosis after exposure to the macrocyclic compound gadobutrol. NDT Plus 3:285-287

27. Morcos SK, Dawson P (2010) Comments on the case report reported by Elmholdt et al. NDT Plus 3:501-502

28. Chrysochou C, Power A, Shurrab AE et al (2010) Low risk for nephrogenic systemic fibrosis in nondialysis patients who have chronic kidney disease and are investigated with gadoliniumenhanced magnetic resonance imaging. Clin J Am Soc Nephrol 5: 484-489

29. Endrikat J, Schwenke C, Prince MR (2015) Gadobutrol for contrast-enhanced magnetic resonance imaging in elderly patients: review of the safety profile from clinical trial, post-marketing surveillance, and pharmacovigilance data. Clin Radiol 70:743-751

30. Prince MR, Zhang H, Zou Z, Staron RB, Brill PW (2011) Incidence of immediate gadolinium contrast media reactions. AJR Am J Roentgenol 196:W138-W143

31. Bettmann MA, Heeren T, Greenfield A, Goudey C (1997) Adverse events with radiographic contrast agents: results of the SCVIR Contrast Agent Registry. Radiology 203:611-620

32. Palkowitsch PK, Bostelmann S, Lengsfeld P (2014) Safety and tolerability of iopromide intravascular use: a pooled analysis of three non-interventional studies in 132,012 patients. Acta Radiol 55:707-714

33. Deurenberg P, Deurenberg-Yap M, Guricci S (2002) Asians are different from Caucasians and from each other in their body mass index/body fat per cent relationship. Obes Rev 3:141-146 